\title{
The Contribution of Working Memory Capacity in Developing the Learner's Oral Proficiency Case Study: Third and Fourth Year Students, Ecole Normale Supérieure of Constantine
}

\begin{abstract}
:
This study is an attempt to highlight the role working memory capacity plays in developing language learners' oral proficiency. It also targets the issue of identifying the very essential component of the same system, the phonological loop, in the speech production process. This article begins with a literature review explaining the different parts of the human memory as a whole, and the major constituents of working memory in particular. This is followed by an experimental study analysis conducted on a population of 45 students in the Department of English in the Teacher Training School of Constantine, and the results of which revealed that the specific characteristics and functions of working memory would be of great significance in improving learners' speaking fluency, thus, confirming and validating our hypothesis.
\end{abstract}

Key words: working memory, Oral proficiency, language learning.

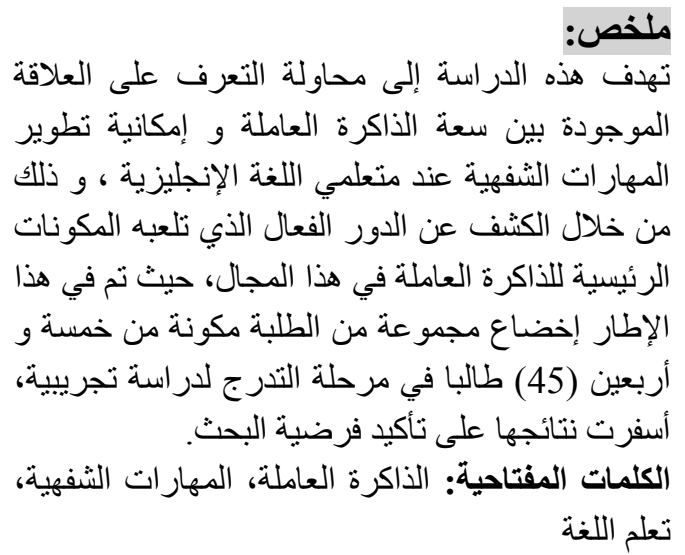

\section{KHERIBET Souheila}

Faculty of Letters and Languages Department of Foreign Languages University of Mentouri Constantine

\section{Introduction :}

Language learning is the concern of neighbouring disciplines such as psychology and psycholinguistics, and which has become a central point of study and inquiry in recent decades. Ellis (2001, p33) argued that the role of memory in language learning has long been of interest in first and second language acquisition. 
On the other hand, Goldstein $(2005,137)$ reported that «you need memory to keep track of the flow of conversation ». It is quite noticeable that the interaction between working memory and speech production is necessary when trying to lead conversation properly, especially that memory is by now recognized to be the most essential function behind the mental activities of storing, maintaining and retrieving the information.

Many investigations have been carried out in an attempt to illustrate how memory can influence the process of foreign language learning. Consequently, psychologists provided reviews about memory and its different components, especially after it has become apparent that any success in foreign language learning is basically attributable to memory capacity. What is observed, as far as foreign language acquisition is concerned, is that most psychologists' attention was mainly consecrated to short term memory or working memory at the expense of other memory systems. In fact, they believe that information in short-term memory is easily accessible compared to the one present in long-term memory, especially when it comes to speaking. A good illustration of that is the one raised by Cook (2002) when she highlighted the close relationship between the phonological loop and language learning. As for the accessibility of information, Haastrup (1991) believes that information that is recently acquired is kept in short term memory, and is directly accessible for further processing, which is not the case of long term memory, from which information should first be retrieved before it can be actually used.

Therefore, to talk about the contribution of the whole memory system in language, first it is important to identify what part of that system is responsible for the fulfilment of the task. Then, it would be possible to draw the link between working memory capacity and foreign language learning.

\section{1-Review of literature}

Memory is "that name given to the ability we have to remember things from the past", (Moxon.2001, p1). The primary objective of the sensory store is just confined to perception. Dehn (2008. p16), too, reported that sensory memory is the first system to process incoming information. He also stipulated that the system is composed of three sub-sensory registers:

- Visual/iconic memory, dealing with seen knowledge.

- Auditory/echoic memory dealing with what is heard

- Haptic memory responsible for processing what is touched

Long term memory, however, is, according to Gathercole and Alloway (2008), that reservoir that is full of past experiences, or of knowledge that has been acquired from minutes to years ago in the life of the individual.

Finally, there is working memory, which is a common and very limited store that is responsible for keeping information acoustically, or simply, that part of the memory system responsible for the temporary maintenance of information (Dehn.2008). Besides, Gathercole and Alloway (2007) suggested 
that the same system is thought to be a mental workspace that handles information in the course of the mental activities (meaning while thinking). Henry (2012), however, stipulated that this particular system is essentially made of three components: The phonological loop, the visuo spatial sketchpad and the central executive. Since the practical focus of the present study is to highlight the relevance of memory in speech production, the emphasis would be therefore directed to working memory because it is the one responsible for temporarily keeping sounds which are necessary while speaking.

This study aims at showing the relevance working memory capacity has on fostering a foreign language learner speech. One significant question that would be raised in this respect is why to concentrate on short term memory and not on the other types of the memory system. For Baddeley (1999) many experiments, mainly the one carried out by Conrad (1964) proved that short term memory relies on some acoustic codes while processing knowledge. By the end of this experiment, Baddeley was able to say that short term memory is particularly closely related to speech, which is not the case of long term memory that handles knowledge in terms of its meaning; nor, it is the case of sensory memory, whose major function is confined to just perception. Furthermore, Ellis $(1996$, p18) reported that working memory capacity has a great impact on learning the grammatical rules of a given language. Finally, Speciale, Ellis and Bywater (2004) while conducting an experiment on undergraduate university students; found that both phonological learning ability and phonological short term memory capacity largely contribute to vocabulary learning. All in all, the sum of the three statements points to basically one conclusion: There is one component in short term memory system that is responsible for handling information phonologically, and the capacity of which is a major cause for successful foreign language learning. Baddeley, Gathercole and Papagno (1998, p158) called that verbal component of working memory referred to by most psychologists as: the phonological loop, a language learning device.

Baddeley (1999) proposed a model of working memory made of three elements: The central executive, which he qualified to be an attentional control system that is supported by two further sub-components: One is verbal, the phonological loop, and the other one is visual commonly known as the visio spatial sketchpad. Therefore, one may deduce that the phonological loop is that verbal component of short term memory that is responsible for keeping trace of spoken knowledge using the process of rehearsal. Subsequently, the focus of this study could be reformulated to be related to showing the role of verbal working memory capacity, or the phonological loop, in developing the individual's speaking skill. 


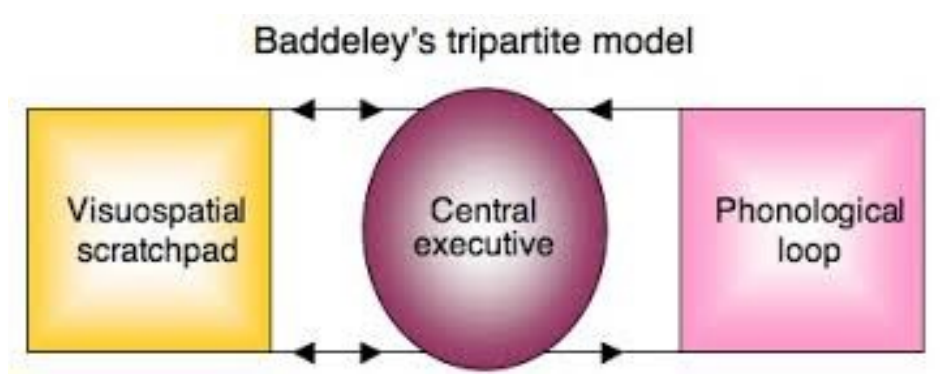

Another equally important insight that should also be questioned is why precisely verbal working memory. In fact, it is widely assumed that to recall information at the level of short term memory, one needs to rehearse using subvocal speech, a role commonly performed by the phonological loop or the articulatory loop, which is the verbal component of short term memory. Baddeley (1999) argued that the phonological loop capacity may be an important determinant of foreign language learning rate, and that a good nonword repetition performance indicates a good memory system, which in its turn leads to good vocabulary learning. The author concluded that the phonological loop is the system whose evolution has developed for the crucial task of language learning.

Ellis (1996) claimed that working memory as measured by non-word repetition test was the best predictor of success in third language learning. Besides, French (2006) stipulated that the simple best predictor of success in learning English at school was the children's accuracy in repeating unfamiliar non words. Eden and Flowers (2008), however reported that non-word repetition tests are basic tools to predict capacities of phonological memory.

On the basis of what has been said so far, the researcher will try to apply the "non- word repetition test" on a population of adult students in Teacher Training School of Constantine studying English, in an attempt to highlight the contribution of working memory capacity in enhancing English language learning in general, especially and in fostering the development of the learner's speaking skill in particular.

The population itself would involve two sets of students that are chosen on the basis of their academic scoring along with their university tests and exams (they especially scored high in the oral expression test). Thus, the two groups will be as: One group of high achievers and another group of low achievers. Two similar sets of tests would be administered to both groups in an attempt to prove that working memory capacity is very influential in the English language acquisition. The expectancy is that high achievers would be able to remember more words compared to low achievers. We assume that high achievers, who are characterized by a good mastery and fluency in producing the spoken form of the language, have a larger working memory capacity 


\section{The Contribution of Working Memory Capacity in Developing the Learner's Oral ProficiencyCase Study: Third and Fourth Year Students, EcoleNormaleSupérieure of Constantine}

compared to low achievers whose failure in remembering words is due to their small working memory capacity.

This study addresses the research question about the relationship between verbal working memory capacity and performance, and the consequent effect on fluency in English in fourth and third year students in the Department of English at the Teacher's Training School of Constantine. Answering this question will inevitably help to see the extent to which our hypothesis is in the right direction; i.e, if learners' working memory capacity is large enough to contain the needed knowledge contributing to speech production, learners would find no difficulty to express themselves in the target language.

\section{2-Method and Design}

\section{2-1-Participants}

Forty five students in the Department of English in the Teacher Training School of Constantine participated in the experiment. Their age varies from 20 to 23 years old. All have undergone similar English studies content in the Department of English of the school for three/four years, often with the same teachers and in the same educational context. A brief interview with them concerning their social background and previous studies revealed that most of them belong to middle class families, whereas their studies in primary, middle and high were carried out in public schools, the product of the same Algerian educational system. As for the English studies, all of them declared that they began learning the English language after finishing the primary school phase (this phase is commonly referred to in the Algerian educational system, as première annéemoyenne). The sample of 45 students were randomly chosen. Randomization is the guarantee that each one of the sample has an equal chance of being selected.

\subsection{Measurement}

To assess the 45 participants' short term memory capacity, a non-word repetition test was used. This latter is based on the premise that subjects have to repeat a list of meaningless words, and in this study, they were asked to repeat a list of non-sense words in a particular order. The list of non-sense words is constituted of mono- syllabic, two, three and four syllable words are randomly arranged.

A non-word repetition test, in its simple definition, is a measure that is commonly used to assess the capacity of subjects to repeat non-sense words and observe the extent to which these latter are able to temporarily store information phonologically, the thing that is linked to the verbal working memory, of interest in this investigation (Tager-Flisberg in Rice et al. 2004). The same test could also be applied to assess the subjects' visual working memory capacity which is primarily linked to another component of the short 
term memory: The Visio-spatial sketch pad. Subsequently, along with this experiment, principles of the non-word repetition test (repeating a sequence of non-sense words in a particular order) are borrowed to be implemented in an Algerian educational setting to achieve the objectives of the g study.

\subsection{Procedure}

The 45 students were received in the traditional learning classroom, where they used to have their usual course, and have not been told about the test. The classroom was equipped with a camera to videotape the whole procedure, including the students' reactions towards the list of words they were supposed to repeat.

The whole group was gathered in order to explain them what would the test be about. Then, they were asked to leave the room knowing that they would be received in pairs.

Once in the classroom, each pair received further explanation about the test: They were told that the test consists of repeating a list of fourteen words in the same order provided in the paper. They were also supposed to read that list for three minutes before repetition. The allocated time for repetition is believed to be sufficient for all learners of different cognitive capacities to remember the content of the list.

The students' performance was assessed on the same paper they read. When they were no longer able to remember a word at a given level, they had to stop repeating. The last correctly repeated word was underlined, and then the students were asked to continue saying the words they were able to recall even in a disordered way.

\section{2-4Analysis and Interpretation}

The analysis of this experiment was divided into three phases.

\section{-Phase 01:}

First, the number of students who were able to remember only some words and then stopped at a particular level was counted and the results were tabulated, and then translated in a graph.

\begin{tabular}{|c|c|c|c|c|c|c|c|c|c|c|c|c|c|c|c|}
\hline $\begin{array}{c}\text { Number of } \\
\text { words }\end{array}$ & 1 & 2 & 3 & 4 & 5 & 6 & 7 & 8 & 9 & $\begin{array}{l}1 \\
0\end{array}$ & $\begin{array}{l}1 \\
1\end{array}$ & $\begin{array}{l}1 \\
2\end{array}$ & $\begin{array}{l}1 \\
3\end{array}$ & 1 & $\begin{array}{c}\text { Tota } \\
1\end{array}$ \\
\hline $\begin{array}{l}\text { Number of } \\
\text { students } \\
\text { rememberin } \\
\text { g only }\end{array}$ & 0 & 3 & $\begin{array}{l}1 \\
3\end{array}$ & $\begin{array}{l}1 \\
0\end{array}$ & 5 & 2 & 0 & 6 & 2 & 1 & 1 & 1 & 0 & 1 & 45 \\
\hline
\end{tabular}

Table 01: Students' VWM Capacity 
The Contribution of Working Memory Capacity in Developing the Learner's Oral ProficiencyCase Study: Third and Fourth Year Students, EcoleNormaleSupérieure of Constantine

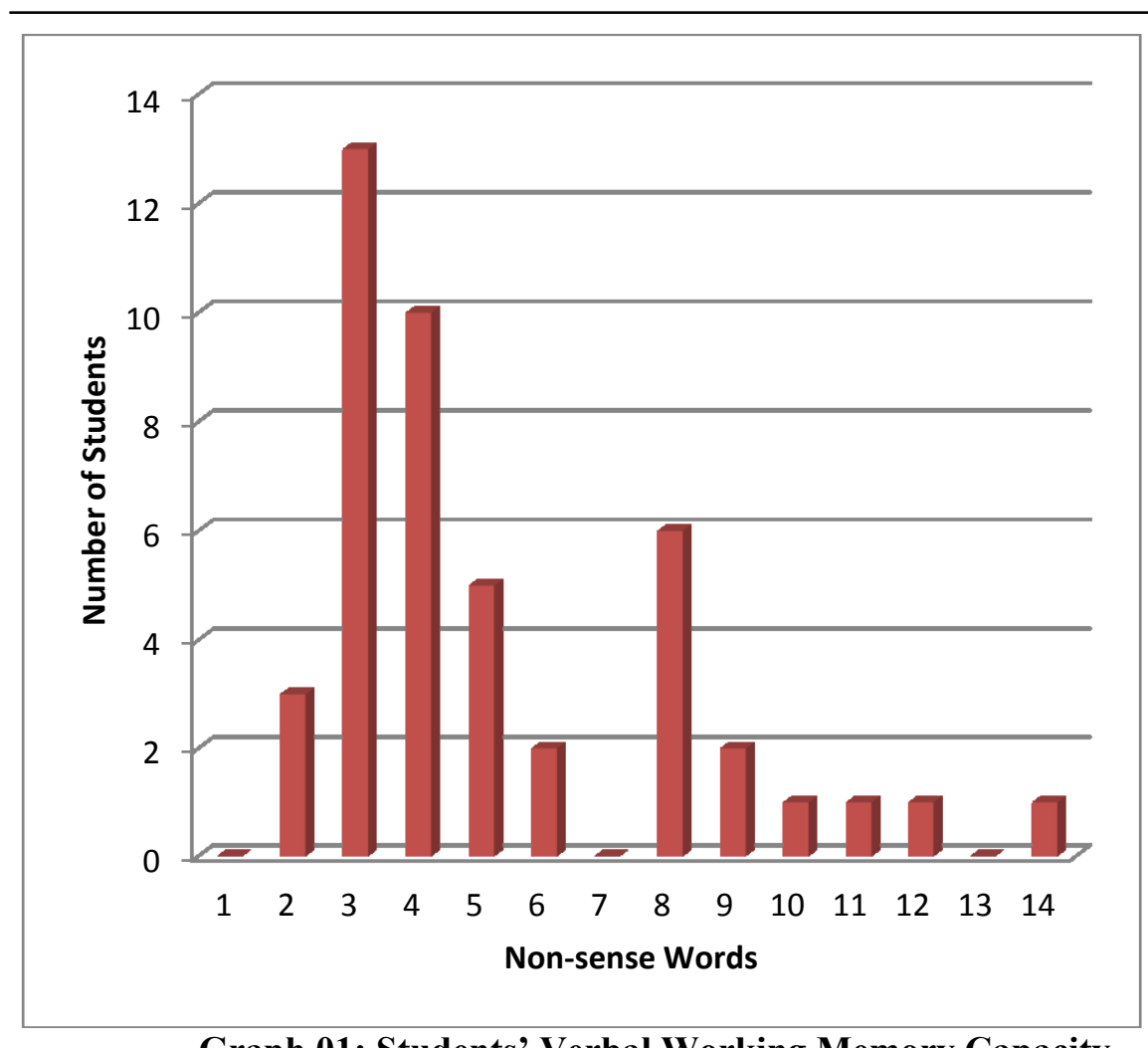

Graph 01: Students' Verbal Working Memory Capacity

The previous graph reflects the number of students who were able to remember only some words, and then stopped at a given level because they completely forget what the next word is. This graph reflects the students' verbal working memory capacity. It can also be notice that there is no correlation between the number of non-sense words and the individuals' capacity as students remembering just three words were thirteen, for seven words no one, whereas eight words, there were six students.

-Phase02:

In this second phase, the total number of students who were able to remember words at each level was counted, taking into consideration the fact that a student who remembered three words automatically is able to remember two and one words. This implies that this same student is counted three times at the three levels. This also means that the student who was able to remember the fourteen words is counted fourteen times reflecting the fourteen levels of the non-sense words. This would be well illustrated in the following table: 


\begin{tabular}{|c|c|c|c|c|c|c|c|c|c|c|c|c|c|c|c|}
\hline $\begin{array}{l}\text { Number } \\
\text { of words }\end{array}$ & 1 & 2 & 3 & 4 & 5 & 6 & 7 & 8 & 9 & $\begin{array}{l}1 \\
0 \\
\end{array}$ & $\begin{array}{l}1 \\
1 \\
\end{array}$ & $\begin{array}{l}1 \\
2 \\
\end{array}$ & $\begin{array}{l}1 \\
3 \\
\end{array}$ & $\begin{array}{l}1 \\
4 \\
\end{array}$ & $\begin{array}{c}\text { Tot } \\
\mathrm{al}\end{array}$ \\
\hline $\begin{array}{c}\text { Number } \\
\text { of only } \\
\text { students } \\
\text { who } \\
\text { remember }\end{array}$ & 0 & 3 & $\begin{array}{l}1 \\
3\end{array}$ & $\begin{array}{l}1 \\
0\end{array}$ & 5 & 2 & 0 & 6 & 2 & 1 & 1 & 1 & 0 & 1 & 45 \\
\hline $\begin{array}{l}\text { Number } \\
\text { of } \\
\text { students } \\
\text { remember } \\
\text { ing }\end{array}$ & $\begin{array}{l}4 \\
5\end{array}$ & $\begin{array}{l}4 \\
5\end{array}$ & $\begin{array}{l}4 \\
2\end{array}$ & $\begin{array}{l}2 \\
9\end{array}$ & $\begin{array}{l}1 \\
9\end{array}$ & $\begin{array}{l}1 \\
4\end{array}$ & $\begin{array}{l}1 \\
2\end{array}$ & $\begin{array}{l}1 \\
2\end{array}$ & $\begin{array}{l}0 \\
6\end{array}$ & $\begin{array}{l}0 \\
4\end{array}$ & $\begin{array}{l}0 \\
3\end{array}$ & $\begin{array}{l}0 \\
2\end{array}$ & $\begin{array}{l}0 \\
1\end{array}$ & $\begin{array}{l}0 \\
1\end{array}$ & \\
\hline
\end{tabular}

Table 02: Percentage of Students Working Memory Capacity Cf explanation of the table under graph $\mathrm{n} 2$

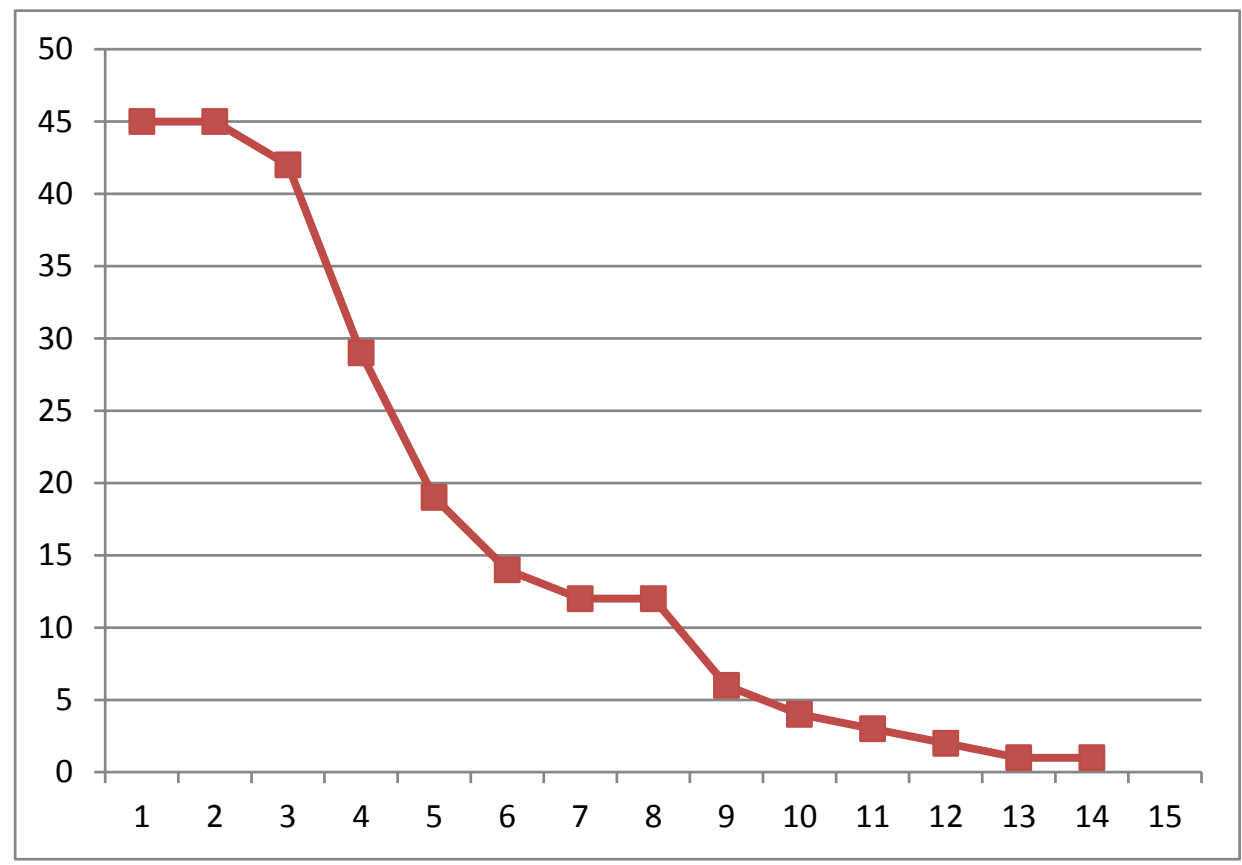




\section{Graph 02:Students' Short Term Memory Capacity}

In the second graph, it is noticed that there is a clear correlation between the number of words and the number of students while remembering: The longer the list is, the less the number of the students would be. i.e $100 \%$ of the respondents were able to remember at least two words; whereas $26.66 \%$ were able to remember seven words, and only $2.22 \%$ was able to remember the fourteen words.

During the experiment, it was noticed that the students while reading the list of the non-sense words were a bit confused. At the end of the experiment, when the students were gathered again in the classroom and asked about that apparent confusion, the majority of them answered that it was because of the words, which they qualified to be unusual, strange, and more interestingly "the words sound English, but they are not".

In fact, the student who reported the last remark (and she was the one who remembered the total number of words) was not wrong. To create those non-sense words, real English words were chosen, one syllable of which was modified so that to get meaningless words that really sound English. Nevertheless, a minority of students were not aware during their repetition that those words were not English. It was observed that they uttered some nonsense words like 'klowledge, astronoby, redolution...'(knowledge, astronomy and revolution); whereas the rest of the words were assumed to be some English words the meaning of which is just ignored, and a simple search in a dictionary would reveal their meaning.

Another interesting remark made by the students who noticed the meaninglessness of the words was that they assured that making the link between the non-sense words and the real English words helped a lot in the retrieval process. Those students were given back their papers, corrected, and then asked to reveal the number of words they were able to recall. It was noticed that their answers varied from three to five words, which, in fact, could be considered as a poor short term memory capacity.

We can deduce the reason behind this poor short term memory capacity. We all know by now that the phonological loop in short term memory encodes information on the basis of their acoustic criteria. Besides, encoding words on the basis of their meaning is a common task performed by long term memory. Therefore, it can be concluded that the students' poor memory capacity is primarily due to the fact that they spent much time making a semantic association between the non-sense words and their equivalents in English, while at the same time, other words are being lost from the system because no rehearsal occurs. That is probably why they could not go beyond the fifth word. 
Four students scored high in the test. They were again individually asked if the association between the non-sense words and the real English words helped them in the process of remembering, and who answered by "to a certain extent" asserted that to remember those words, they rather repeated the words loudly and many times. Besides, they declared that the way the words were written and organized on the paper also contributed to the fulfilment of the remembering process. This may imply that to successfully remember those non-sense words, they relied, in addition to the verbal component of their short term memory (the phonological loop), on the visio-spatial sketchpad, which is another component of the working memory.

\section{Phase 03:}

In the last phase of the experiment, the results of the test to the students' academic scores, were compared to check whether the test results correlate with the students' scores at school. What was found confirmed the hypothesis. In fact, the two students who scored very low in the test (they were able to remember only the two first words), were very low scorers at school, and they even repeated one academic year. However, the two students who scored high in the test (one student stopped at level twelve, whereas the other one, was able to remember the entire list), they are very excellent fourth year students with great academic scores. Furthermore, they speak English fluently with a satisfactory mastery of grammar and phonological rules.

For this, the verbal component of the individual's short term memory largely contributed to a successful foreign language learning especially to the development of the speaking skill in particular.

\section{Conclusion:}

This study considerably helped in explaining how working memory capacity contributes in developing the learners' oral proficiencies. The nonword repetition test implemented in the experimentation, and which is generally used to show the extent to which people are able to recall acoustic knowledge at the level of the verbal component of working memory, largely confirmed the stated hypothesis. The obtained results' analyses were favourable in that they clearly validate our assumption, that, in fact, working memory capacity influences the development of the learner's speech production.

Therefore, working memory is rudimentary in developing learners' oral skills. This could be achieved through providing opportunities to learners to use the language orally and exposing them to authentic materials, concentrating basically on speech. For it is the only way to assure that the knowledge being processed in the memory system at the level of working memory is acoustic. By doing so, the student would develop the habit of easily using the aural skills, a common activity fulfilled by the working memory, at the expense of handling knowledge in accordance to meaning, which is basically a long term 
memory task. We believe this to be one effective way to develop learners' speaking skill, since we assume that much speech production means more use of the verbal component of the short term memory, the phonological loop, and more practice means more rehearsal. Knowing that the phonological loop is a sub-component of working memory; it is responsible for retaining information verbally over short periods of times through a rehearsal process, which serves to keep verbal information active in the phonological store.

\section{References:}

Baddeley.A.D (1999): Essential of Human Memory. Psychology Press Ltd. Baddeley.A.D,Gathercole.S.E, and Papagno.C (1998): The Phonological Loop as a Language Learning Device. Psychological Review.

Cook.V (2002): Portraits of the L2 User. Second Edition. Multilingual Matters Ltd

Dehn.M.J (2008): Working Memory and Academic Learning: Assessment and Intervention, John Wiley and Sons.

Eden.G.F and Flowers.L (2008): Learning, Skill Acquisition, Reading and Dyslexia. John Wiley and Sons

Ellis.N.C (1996): Sequencing in SLA: Phonologicql memory, Chunking and Points of Order. Studies in Second Language Acquisition.

Ellis.N.C (2001): Cognition and Second Language Instruction, Cambridge University Press, New York

French.M (2006): Phonological Working Memory and Second Language Acquisition: A Developmental Study of Francophone Children Learning English in Quebec. Edwin Mellen Press

Gathercole.S.E and Alloway .T.P (2007): Understanding Working Memory: A Classroom Guide. Harcourt Assessment: Procter House.

Gathercole.S.E and AllowayT.P (2008): Working Memory and Learning: A practical Guide for Teachers. SAGE Publication Ltd

Goldstein (2005) "Cognitive Psychology - Connecting Mind, Research, and Everyday Experience", Thomson Wadsworth TM 2005

Haastrup.K (1991): Lexical inferencing Procedures or talking about words. Gunder NAN Verlag Tub-ingen

Henry.L (2012): The development of Working Memory in Children. SAGE Publication Ltd.

Moxon.D(2000): Memory. Heinman Educational Publishers.

Special.G, Ellis.N.C and Bywater.T (2004): Phonological Sequence Learning and Short Term Store Capacity Determine Second Language Vocabulary Acquisition. Applied Second Language.

Rice.M.L and Warren.S.F (2004): Developmental Language disorders: From Phenotype to Etiologies . Lawrence Elbaum Associates, Publishers. London 


\author{
APPENDIX \\ List of Non-sense Words \\ Read the following words silently \\ -Tharg \\ 2-Pharg \\ 3-Embeddlement \\ 4-Daughder \\ 5-Regundancy \\ 6-Dravery \\ 7-Klowledge \\ 8-Lostage \\ 9-Quemerang \\ 10-Redolution \\ 11-Blever \\ 12-Awale \\ 13-Carloon \\ 14-astronoby
}

